This item was submitted to Loughborough's Research Repository by the author.

Items in Figshare are protected by copyright, with all rights reserved, unless otherwise indicated.

\title{
Quantifying the effect of window opening on the measured heat loss of a test house
}

PLEASE CITE THE PUBLISHED VERSION

http://www.leedsbeckett.ac.uk/leeds-sustainability-institute/seeds-conference-2015/

PUBLISHER

Leeds Beckett University

VERSION

AM (Accepted Manuscript)

\section{PUBLISHER STATEMENT}

This work is made available according to the conditions of the Creative Commons Attribution-NonCommercialNoDerivatives 4.0 International (CC BY-NC-ND 4.0) licence. Full details of this licence are available at: https://creativecommons.org/licenses/by-nc-nd/4.0/

\section{LICENCE}

CC BY-NC-ND 4.0

\section{REPOSITORY RECORD}

Jack, Richard, Dennis L. Loveday, David Allinson, and Kevin J. Lomas. 2019. "Quantifying the Effect of Window Opening on the Measured Heat Loss of a Test House". figshare. https://hdl.handle.net/2134/18807. 


\title{
SEEDS International Conference
}

\section{Quantifying the Effect of Window Opening on the Measured Heat Loss of a Test House}

\author{
Richard Jack, Dennis Loveday, David Allinson, Kevin Lomas \\ Building Energy Research Group, Department of Civil and Building Engineering, Loughborough \\ University, Loughborough, Leicestershire, LE11 3TU, United Kingdom.
}

Keywords: Heat loss measurement, window opening, air tightness, co-heating.

\begin{abstract}
Opening windows is a common method for controlling air temperature, moisture, air quality and odours in dwellings. Opening a window in winter will increase the heat loss from a house, the additional heat loss will depend on the size of the window opening and the length of time for which the window is open. However, window opening behaviour is unpredictable, varying widely between different dwellings and occupants making it difficult to incorporate into predictions of energy consumption.

This paper reports the results of an investigation to quantify the impact of window opening on the measured air tightness and total heat loss in a detached, timber framed test house built in the year 2000 to contemporary building standards, and located at Loughborough University. Blower door tests were used to measure the increase in ventilation caused by opening windows. The additional heat loss due to this ventilation was predicted using a simple model and then compared to the whole house heat loss as measured by a co-heating test. A linear relationship between window opening area and additional ventilation was found, independent of window location. This relationship was used to quantify the additional heat loss for a variety of window opening behaviours. The results show that window opening does not significantly increase heat loss rates in this particular house for all but the most extreme window opening behaviours. The implications of these results for different types of dwelling are discussed.
\end{abstract}

\section{NOMENCLATURE}

Air permeability envelope area: For air permeability testing this includes the area of all perimeter walls, the roof of the highest storey included in the test and floor of the lowest story. The volume of the dwelling is contained within these boundaries (ATTMA, 2010). 
HLC: Heat Loss Coefficient, a measure of the rate of heat loss from a dwelling measured in Watts/Kelvin.

In-use: A term used to describe a dwelling which is occupied.

n50: Is a measure of air tightness; it is the proportion of the air contents of the house that is replaced per hour at a pressure difference of 50Pa. It is calculated by dividing the air leakage rate at a pressure difference of 50 Pascals by the building volume and has units of $1 / \mathrm{h}$, sometimes also written as ACH/h (air changes/hour) (ATTMA, 2010).

q50: Another common measure of air tightness; the air leakage rate at a pressure difference of $50 \mathrm{~Pa}$ is divided by the envelope surface area of the building, with units of $\mathrm{m}^{3} / \mathrm{hm}^{2}$ (surface area). This is the metric used in UK building regulations (ATTMA, 2010).

SAP: The UK Government's Standard Assessment Procedure for Energy Rating of Dwellings, which is the standard method used in the UK to predict thermal performance and energy consumption of domestic buildings. There is also a Reduced Data Standard Assessment Procedure (RdSAP), which is used for existing dwellings.

\section{INTRODUCTION}

Window opening is a commonly used method for controlling temperature in dwellings, but is also often used to control other conditions such as moisture, air quality and odours. During the winter heating season, this window opening will cause an increase in heat loss from the dwelling which will depend upon the duration and extent of opening. This paper uses an experimental approach to quantify the size of the additional heat loss that is due to window opening in a single detached house, for a variety of window opening behaviours. This is then compared with the total heat loss from the house as measured by co-heating tests to provide an insight into the relative effect that window opening could have in comparison to other heat loss mechanisms.

Clearly the relative impact of window opening will be dependent both upon window opening behaviour and the thermal performance of the dwelling. For dwellings with a lower HLC (i.e. which are higher performing) the same window opening behaviour will be relatively more significant in comparison to the baseline performance of the dwelling. This relationship is investigated and the implications for window opening in a variety of dwelling types are discussed.

The co-heating tests carried out by Leeds Beckett University represent the largest dataset of HLC measurements currently in existence (Figure 1) (image sourced from Stafford et al. 2012). These results give some context for the typical HLC of UK dwellings, although most of the measurements were carried out in newly-built dwellings and the dataset is therefore likely to be skewed towards dwellings with higher thermal performance. 


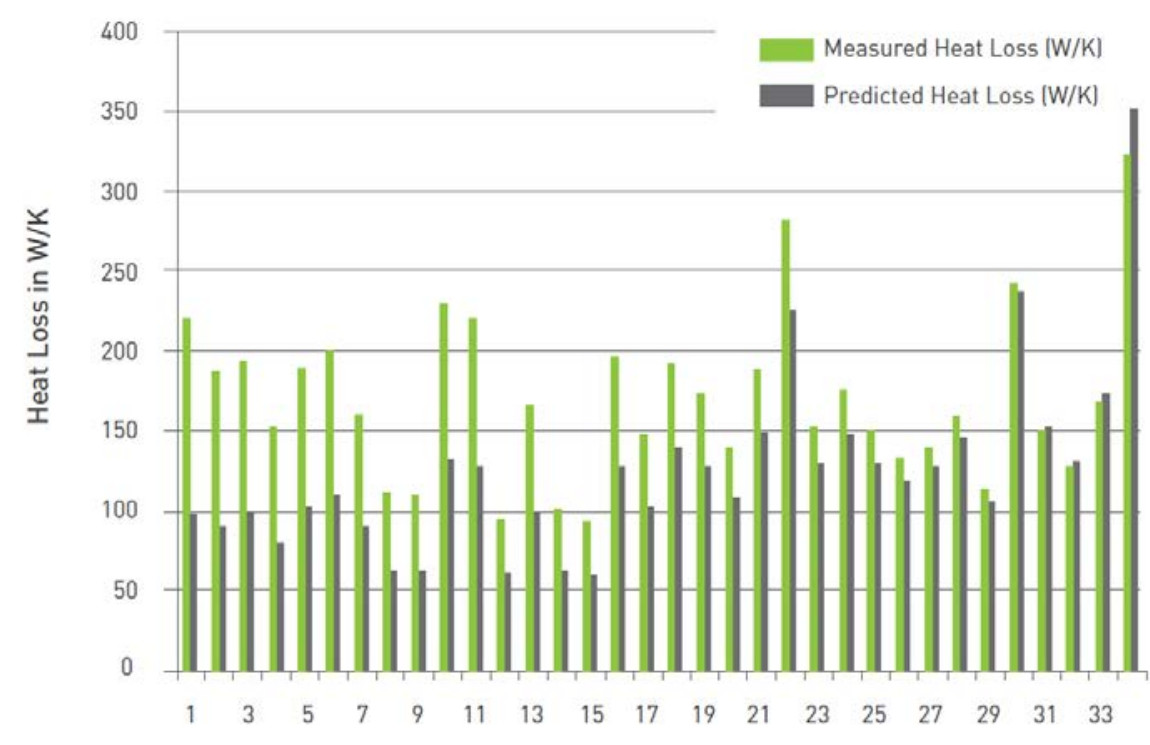

Figure 1: Co-heating test results measured by Leeds Beckett University, image sourced from (Stafford et al., 2012).

The findings of this study will be useful in post-occupancy evaluations of building performance. They may help to explain commonly observed discrepancies between predicted and in-use energy consumption, where energy consumption is almost always higher than predicted (Zero Carbon Hub and NHBC Foundation, 2010), as the effect of winter window opening is not accounted for in models such as the UK's SAP (BRE, 2013). They also provide guidance as to effect of a variety of window opening behaviours, which is important given the wide variation of possible window opening behaviours and the consequent difficulty in defining 'typical' window use.

This research has been integral to the development of the Loughborough In-Use Heat Balance (LIUHB) method, a new test which uses monitored data to measure the HLC of a dwelling while it is in-use, with little impact on the occupants (Jack et al., 2015). The findings presented in this paper have contributed to calculating the estimated accuracy of the HLC measurement by an LIUHB test of $\pm 15 \%$.

There have been several studies investigating window opening behaviour across Europe, Fabi et al (2012) presented a comprehensive literature review of the collected evidence. This showed that window opening in domestic buildings is driven primarily by external temperature, but also a wide variety of further contributing factors such as solar radiation, wind speed, rainfall, age, gender, dwelling type, orientation of the windows, occupancy, time of day, room use and indoor air quality (ibid). Of particular significance for this study is that window opening during winter was commonly found to occur, though at a reduced rate compared to other seasons due to the reduced temperature (ibid). This finding was repeated in an on-street survey carried out in the UK by Fox (2008). The literature also suggests that window opening is linked to occupancy, and therefore is more likely in the morning and evening (Dubrul, 1988; Fox, 2008; Johnson and Long, 2005), and that the rooms in which the 
windows were opened most frequently were the bathrooms, bedrooms and the kitchen (Fox, 2008).

Only one paper reporting a similar aim to this study, i.e. measuring the link between window opening and additional ventilation, was found. For that paper, Howard-Reed et al carried out more than 300 air change rate measurements in two occupied houses in the USA using a tracer gas decay method (Howard-Reed et al., 2002). The measurements showed a linear relationship between the measured increase in air change rate and window opening width, measured at a single window in each house (Howard-Reed et al., 2002).

\section{METHODS}

Two methods of building performance measurement have been used in this study: blower door tests and co-heating tests. The blower door test is the industry standard method for measuring the air tightness of dwellings, as demonstrated by its mandated use in the UK's building regulations (H.M. Government, 2013). The test involves applying a pressure differential across a building envelope, usually using portable fans installed in a temporary door frame (an example of which is shown in-situ in Figure 3), and measuring the air flow rate required to maintain this pressure differential (ATTMA, 2010).

One disadvantage of blower door tests is that the air tightness is measured at an elevated pressure difference, meaning the air tightness at a natural pressure difference cannot be directly determined (ASTM, 2012). Tracer gas decay methods can also be used to measure the air tightness of dwellings and allow direct measurement of the air tightness at natural pressure difference. The technique involves monitoring the decay of an introduced tracer gas (commonly $\mathrm{CO}_{2}$ ) from which the volume flow rate of outgoing air can be inferred (ASTM, 2012). It has also been shown that this method can be carried out in occupied dwellings using the $\mathrm{CO}_{2}$ produced by the occupants as the gas source (Roulet and Foradini, 2002). The tracer gas decay method has the disadvantage of requiring a time period of several hours in order to carry out a measurement (ASTM, 2012).

Co-heating has become the most widely used method to measure the whole house thermal performance of dwellings (Stafford et al., 2012). It involves carefully measuring the energy required to electrically heat the interior of a house to a constant elevated temperature (typically $25^{\circ} \mathrm{C}$ ) for an extended period (usually around 2 weeks) (Johnston et al., 2013). The output of the test is the HLC of the house, which is calculated based upon the rate of heat input and the internal-external temperature difference after the influence of solar heating has been accounted for (ibid).

Various methods have been suggested to account for solar gains (Butler and Dengel, 2013), in this study the method described by Siviour has been used (Everett, 1985). The Siviour method uses a linear regression analysis to correct for the influence of solar gains; the daily mean values for global solar irradiance and electrical heating power are plotted against each other, with both terms divided by the temperature difference $(\Delta T)$ as shown in Figure 2 (ibid). The y-intercept of a linear regression is the measured HLC, so that the HLC in the hypothetical example shown in Figure 2 is $183 \mathrm{~W} / \mathrm{K}$. 


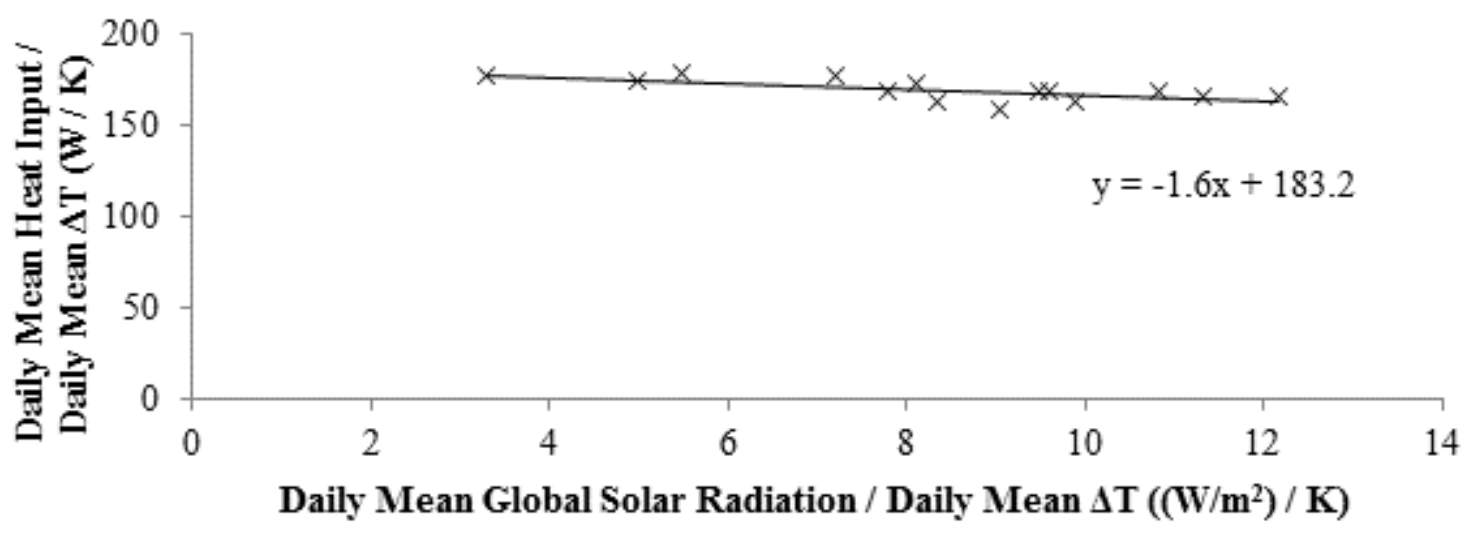

Figure 2: Hypothetical example of the Siviour co-heating analysis method. Each data point represents the mean readings taken over a 24 -hour period.

All testing was carried out in the Holywell test house located on the Loughborough University campus, in the East Midlands area of England (a test house simply refers to a normal house which is used specifically for experimentation). The Holywell test house is a small, timber framed, detached building, with a total floor area of $59.8 \mathrm{~m}^{2}$ and an envelope surface area of $166.1 \mathrm{~m}^{2}$ (see Figure 3). It was built in 2000 to contemporary building standards, and has been used as a test house since 2009. The house has uninsulated suspended floors, insulated cavity walls and 200mm of loft insulation installed. An RdSAP assessment (BRE, 2011) of the house resulted in an estimated total Heat Loss Coefficient (HLC) (including ventilation heat loss) of $180 \mathrm{~W} / \mathrm{K}$.
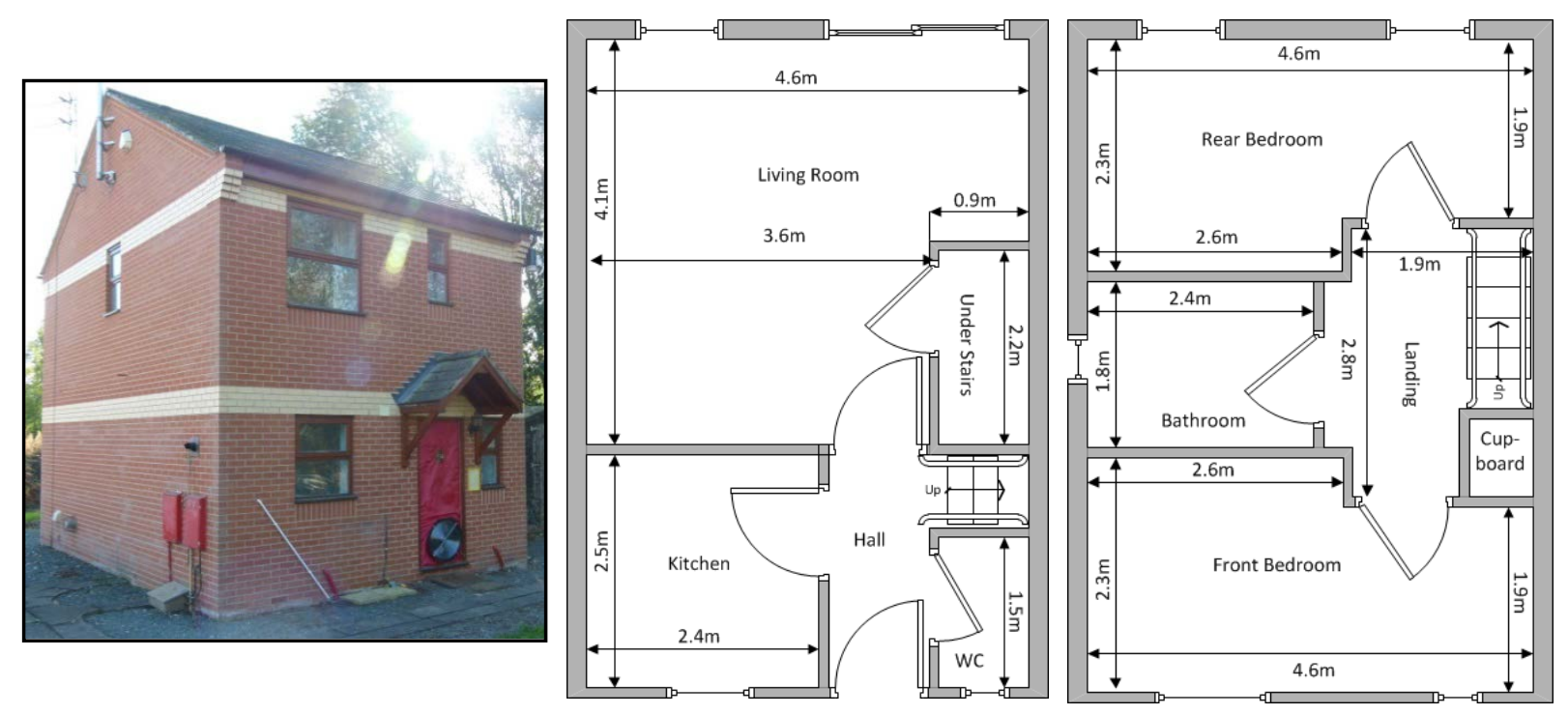

Figure 3: The Holywell test house (left), ground floor plan (middle) and first floor plan (right).

The HLC of the house was measured by co-heating tests; in total three tests were carried out over a period of one year and the mean measured HLC from the three tests was taken as the final measurement. The tests were carried out according to the method described by Johnston et al (Johnston et al., 2013), and the data was analysed to correct for solar gains using the method described by Siviour (Everett, 1985). The uncertainty of the HLC measured by co- 
heating tests is difficult to estimate directly due to the process of estimating the solar gains, though some research has suggested that an accuracy of approximately $\pm 10 \%$ is reasonable (Alexander and Jenkins, 2015)

The baseline infiltration rate of the house, with all openings closed, was measured using the blower door method (ATTMA, 2010) and Model 4 Minneapolis Blower Door equipment (shown in place in Figure 3). To ensure a reliable baseline measurement, the test was repeated three times, with the equipment located in both the front and patio doors. No significant variation was found between the results.

The added ventilation due to window opening was also measured using the blower door apparatus. Each manually operable window in the house was opened to different extents and a blower door test was carried out for each window opening state. The windows were located throughout the house in the kitchen, living room, bathroom, front and rear bedrooms; in total eight blower door tests were carried out.

The range of tests that could be carried out was limited, as after the window opening area exceeded approximately $0.6 \mathrm{~m}^{2}$ there was too much variation in the building pressure measurement to record accurate results. The air change rate at 50 Pascals pressure difference across the building (n50, units $1 / \mathrm{h}$ ) was measured by the blower door test, and was converted into an infiltration rate at normal pressure difference using the K-P model (Sherman, 1987), in which the n50 value is simply divided by 20 .

Local weather conditions were measured at the Loughborough University weather station, which is located approximately $1 \mathrm{~km}$ from the Holywell test house.

\section{RESULTS}

Three co-heating tests were carried out to establish the baseline HLC of the Holywell test house. The three tests gave a very consistent set of results (Table 1), and the mean of the three measurements, $170 \mathrm{~W} / \mathrm{K}$, was used as the baseline HLC.

\begin{tabular}{|l|l|l|}
\hline Test & Test Date (month) & HLC (W/K) \\
\hline 1 & November 2012 & 169 \\
\hline 2 & June 2013 & 173 \\
\hline 3 & October 2013 & 167 \\
\hline MEAN & & 170 \\
\hline
\end{tabular}

Table 1: Results of the co-heating tests.

Three blower door tests were carried out to establish the baseline air infiltration rate of the Holywell house (Table 2), the mean measured infiltration rate of $0.87 \mathrm{ACH} / \mathrm{h}$ was used as the final measurement. The baseline measurements show that the Holywell house is relatively leaky, with a q50 value of $15 \mathrm{~m}^{3} / \mathrm{hm}^{2}$, which is considerably higher than the $10 \mathrm{~m}^{3} / \mathrm{hm}^{2}$ limit required of new dwellings in the current building regulations (H.M. Government, 2013). 


\begin{tabular}{|l|l|l|l|}
\hline Test & $\mathbf{q 5 0} \mathbf{( m}^{\mathbf{3}} / \mathbf{h m}^{2}$ @ 50Pa) & $\mathbf{n 5 0} \mathbf{( A C H} / \mathbf{h} @ \mathbf{5 0 P a})$ & $\mathbf{n}(\mathbf{A C H} / \mathbf{h})$ \\
\hline 1 & 15.2 & 17.6 & 0.88 \\
\hline 2 & 14.9 & 17.3 & 0.87 \\
\hline 3 & 15.1 & 17.5 & 0.87 \\
\hline$M E A N$ & 15.0 & 17.5 & 0.87 \\
\hline
\end{tabular}

Table 2: Results of the baseline blower door tests (all openings closed).

The blower door tests to measure the effect of various window openings were carried out consecutively on the same day as the baseline measurements (19/11/13) to ensure that there was little variation in the testing conditions between measurements. The heating in the house was left off during the day prior to the test to equalise the internal and external temperature as much as possible and the wind speed was relatively low on the day of testing (Table 3).

\begin{tabular}{|l|l|l|}
\hline Internal Temperature $\left({ }^{\mathbf{0}} \mathbf{C}\right)$ & External Temperature $\left({ }^{\mathbf{0}} \mathbf{C}\right)$ & Wind Speed $(\mathbf{m} / \mathbf{s})$ \\
\hline 8.2 & 4.0 & 2.0 \\
\hline
\end{tabular}

Table 3: Mean conditions during the blower door tests.

The results of the nine blower door tests showed a close linear relationship between the measured infiltration rate and the additional opening area caused by the window opening (which was measured for each test). There was an additional measured infiltration rate of 3.8 air changes per hour for each additional $\mathrm{m}^{2}$ of opening area (Figure 4). This relationship was independent of which storey, room and facade in which the window was located (Table 4).

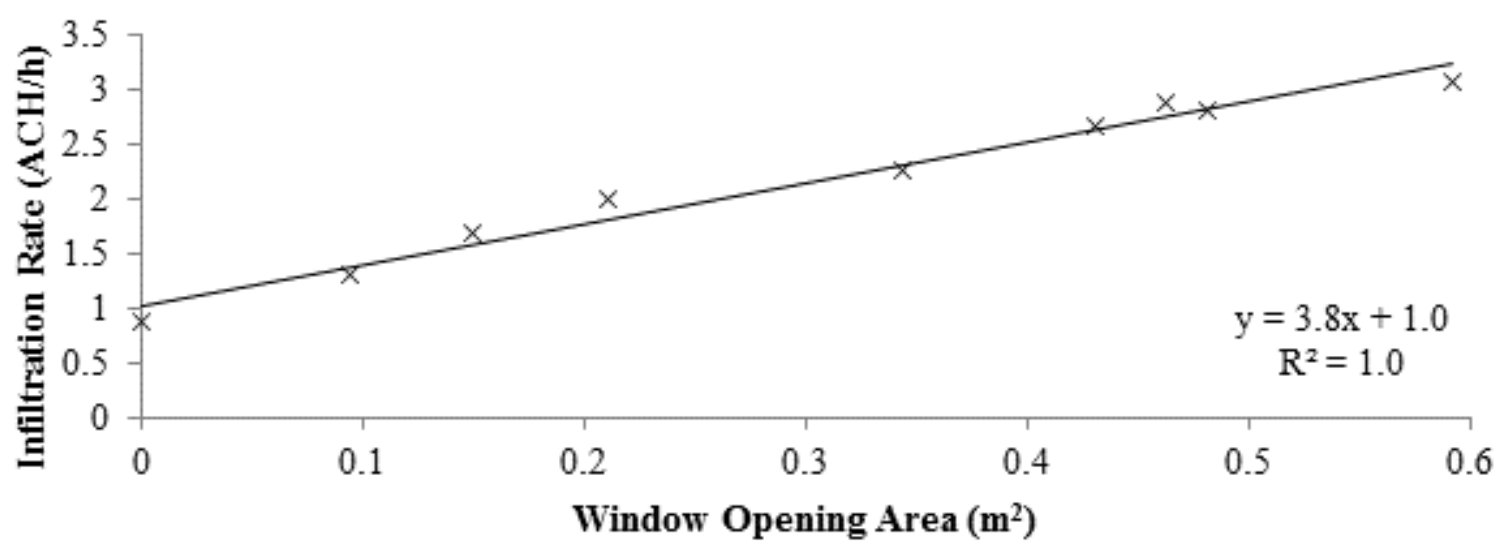

Figure 4: Results of the blower door tests with window opening.

\begin{tabular}{|l|l|r|r|r|r|}
\hline Test & Window & Opening Area $\mathbf{( m}^{\mathbf{2}} \mathbf{)}$ & $\mathbf{q 5 0} \mathbf{( m}^{\mathbf{3}} \mathbf{\mathbf { h m } ^ { \mathbf { 2 } } \mathbf { ) }}$ & $\mathbf{n 5 0} \mathbf{( 1 / h )}$ & $\mathbf{n} \mathbf{( A C H / h )}$ \\
\hline 1 & Rear Bed Right & 0.09 & 22.5 & 26.1 & 1.3 \\
\hline 2 & Rear Bed Right & 0.15 & 29.1 & 33.8 & 1.7 \\
\hline 3 & Rear Bed Right & 0.21 & 34.4 & 40.0 & 2.0 \\
\hline 4 & Bathroom & 0.34 & 39.0 & 45.2 & 2.3 \\
\hline 5 & Kitchen & 0.43 & 46.2 & 53.6 & 2.7 \\
\hline 6 & Rear Bed Left & 0.46 & 49.8 & 57.8 & 2.9 \\
\hline 7 & Living Room Left & 0.48 & 48.4 & 56.1 & 2.8 \\
\hline 8 & Front Bed Right & 0.59 & 53.3 & 61.8 & 3.1 \\
\hline
\end{tabular}

Table 4: Details of the window openings and results for each blower door test (also shown in Figure 4). 
The linear relationship found between window opening area and additional air infiltration allow the additional heat loss associated with a given window opening area and length of opening to be easily calculated, for a set of internal and external conditions in the Holywell house. The estimated additional heat loss for this house due to window opening $\left(\Delta \mathrm{Q}_{\mathrm{w}}\right)$ is:

$\Delta \mathrm{Q}_{\mathrm{w}}=\rho \mathrm{C}_{\mathrm{P}} \Delta \mathrm{T} \Delta \mathrm{v} \mathrm{V}$

Where $\rho$ is the density of air $\left(\mathrm{kg} / \mathrm{m}^{3}\right)$ at the volumetrically weighted mean indoor temperature during the window opening, $\mathrm{C}_{\mathrm{p}}$ is the specific heat capacity $(\mathrm{J} / \mathrm{kgK})$ of air at the volumetrically weighted mean indoor temperature, $\Delta \mathrm{T}$ is the internal-external temperature difference $(\mathrm{K}), \Delta \mathrm{v}$ is the additional ventilation due to window opening (converted to $\mathrm{ACH} / \mathrm{s}$ ) and $\mathrm{V}$ is the internal volume of the house $\left(\mathrm{m}^{3}\right)$. It is likely that the air temperature close to the window, where the air infiltration occurs, will be slightly different from the mean indoor temperature. As the heat loss is being considered from the house as a whole and the open window could be located anywhere in the house, the volumetrically weighted mean internal temperature was used to calculate the additional heat loss.

The empirically defined relationship between window opening area and additional ventilation in the Holywell house (3.8 additional ACH/h per $\mathrm{m}^{2}$ opening area) has been used to create Figure 5, which shows the measured additional heat loss that a variety of window opening behaviours would cause. In order to give a visual reference, the total HLC of the Holywell house with all windows closed is been displayed on the y-axis; this figure is included as a reference value and is not an additional heat loss as indicated by the axis label.

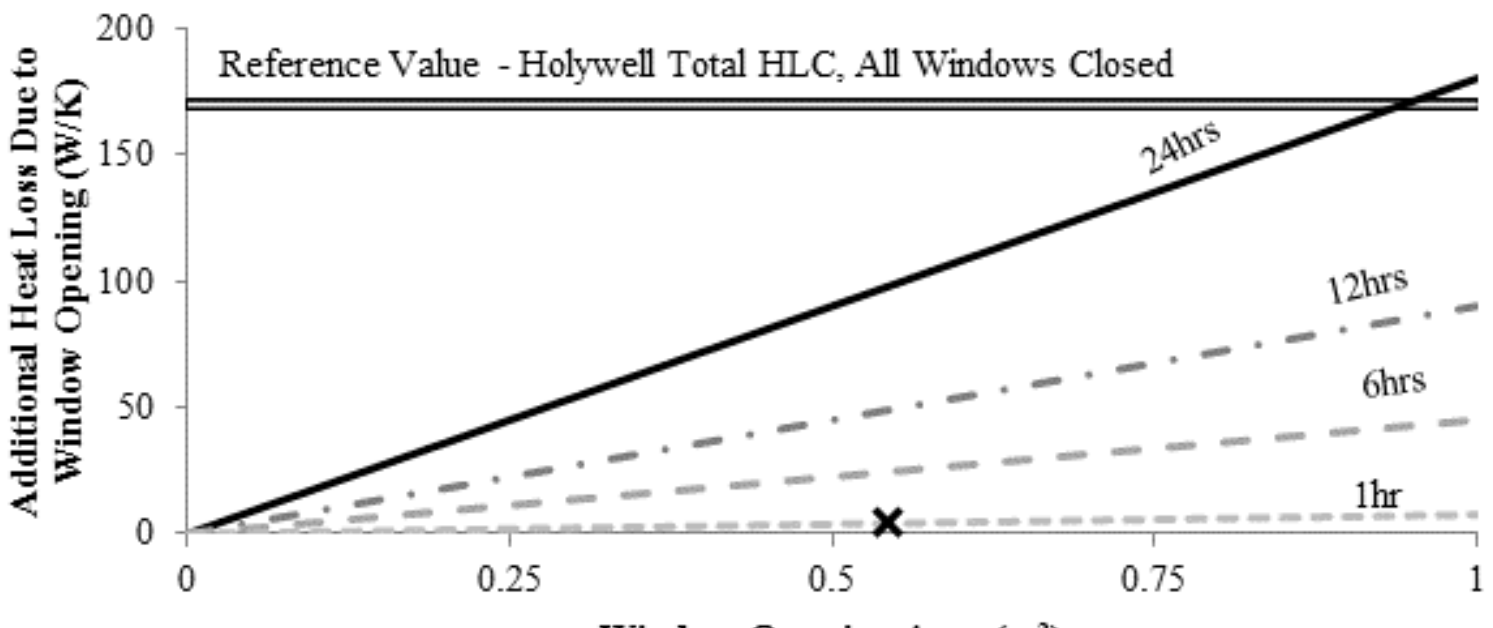

Window Opening Area $\left(\mathrm{m}^{2}\right)$

Figure 5: The relationship between window opening and additional heat loss in the Holywell test house. The labelled trend lines show the effect of a window opening area of different sizes for different lengths of time per day, the $X$ shows the additional heat loss due to the window opening behaviour defined below.

It is clear in Figure 5 that window opening does have the potential to cause a significant additional heat loss in comparison to the total heat loss of the house. In order to judge the size of the impact, the window opening behaviour in the house would have to be defined. As 
described earlier, this is likely to be highly variable between houses and it is extremely difficult to define a 'typical' window opening behaviour.

Figure 5 shows that in the Holywell house, a window opening of area of $0.94 \mathrm{~m}^{2}$ (which could occur in a single window or a combination of different windows) for 24 hours per day would double the heat loss rate of the house. This seems to be a very unlikely scenario during winter however; a more realistic estimate of the effect of window opening is shown by an $\mathrm{X}$ in Figure 5. This shows the effect of one possible daily window opening behaviour where the kitchen window is opened between 18:30-18:45 (during cooking), the bathroom window is opened between 7:30-8:00 (during washing) and windows are opened in both bedrooms between 8:00-8:15 (after sleeping). In all cases the windows are opened to their largest possible extent.

This window opening behaviour has been included simply to provide an indication of the effect of a plausible example of window opening behaviour and is chosen based upon the literature that is available regarding the time of use of windows (Dubrul, 1988; Fox, 2008; Johnson and Long, 2005). The estimated additional heat loss caused by this window opening behaviour is $4.1 \mathrm{~W} / \mathrm{K}$, which is $2.4 \%$ of the total HLC of the building.

The impact of window opening relative to the total heat loss from a dwelling is associated both with window opening behaviour and the baseline performance of the dwelling. The total heat loss is comprised of two components, the fabric and infiltration heat loss:

Total Heat loss $=$ Fabric heat loss + Infiltration heat loss $=\sum \mathrm{UA} \Delta \mathrm{T}+1 / 3 \mathrm{n} \mathrm{V} \Delta \mathrm{T}$

Where $\sum U A$ is the sum of the $U$-value of each building element $\left(\mathrm{W} / \mathrm{m}^{2}\right)$ multiplied by its surface area $\left(\mathrm{m}^{2}\right), \mathrm{n}$ is the air permeability of the dwelling $(\mathrm{ACH} / \mathrm{h}), \mathrm{V}$ is the internal volume of the dwelling $\left(\mathrm{m}^{3}\right)$ and $\Delta \mathrm{T}$ is the internal-external temperature difference. For ease of comparison both sides of the equation can be divided by $\Delta \mathrm{T}$, so that it is stated in terms of heat loss rates rather than total heat loss. The total HLC of the Holywell test house, as measured by co-heating tests, is broken down into a fabric component of $130 \mathrm{~W} / \mathrm{K}$ and an infiltration component of only $40 \mathrm{~W} / \mathrm{K}$ (infiltration heat loss $=1 / 3 \mathrm{n} \mathrm{V}$, as in (EQ 2)):

Total HLC $=$ Fabric heat loss rate + Infiltration heat loss rate $=130+40=170 \mathrm{~W} / \mathrm{K}$

Window opening only affects the infiltration heat loss from the building, specifically by changing the air permeability of the house. A comparison of (EQ 2) and (EQ 3) makes it clear that a very large change in the air infiltration rate would be required in order to cause a significant change in the total heat loss rate from the Holywell test house. Clearly this is a relationship specific to a particular dwelling, though the heat loss due to window opening is related to the opening area and therefore is not affected by the fabric performance of the dwelling or its air tightness. This means that in dwellings with lower heat loss rates the effect of window opening will be relatively larger. Comparison of the equations also suggests that the effect of window opening will be more pronounced for smaller dwellings (with a lower internal volume). 
The relationship between the total HLC of a dwelling and the relative impact of the window opening (shown as a percentage increase in the total heat loss from the dwelling) for a range of window opening behaviours is shown in Figure 6. The figure shows the impact of a range of window opening behaviours, causing additional heat losses ranging from $1 \mathrm{~W} / \mathrm{K}$ to $15 \mathrm{~W} / \mathrm{K}$; the relationship for the window opening behaviour defined in this paper is shown by the solid line on the chart.

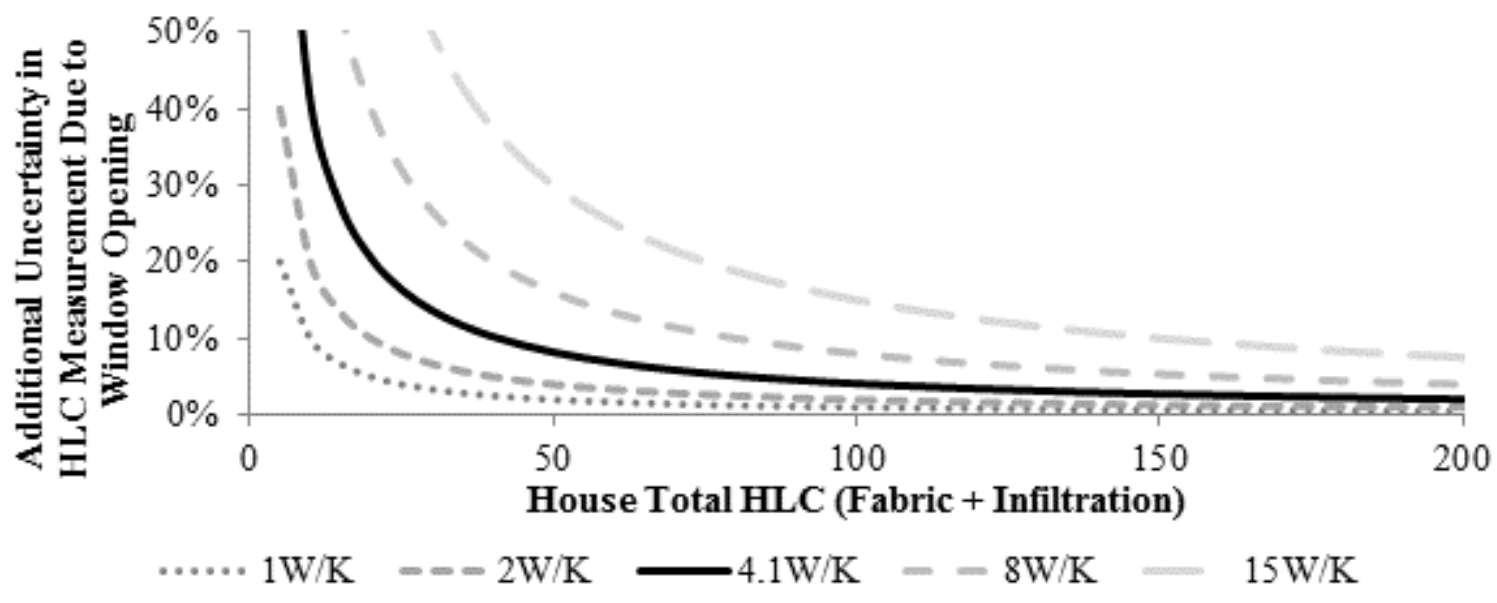

Figure 6: The relationship between the total HLC of a house and the percentage additional heat loss caused by a range of window opening behaviours. The window opening behaviour defined in this paper (which results in 4.1W/K additional heat loss due to window opening) is shown by the solid line.

Figure 6 highlights that the additional heat loss due to window opening for most behaviours is relatively small for the majority of dwellings, but rapidly increases in dwellings of higher thermal performance (and hence a lower HLC) or for more extreme window opening behaviours. The window opening behaviour defined in this paper (shown by a solid line in Figure 6) causes an additional heat loss of greater than $5 \%$ for dwellings with an HLC lower than $75 \mathrm{~W} / \mathrm{K}$, and greater than $10 \%$ for dwellings with an HLC lower than $40 \mathrm{~W} / \mathrm{K}$. It is important to note that the relationship shown in Figure 6 is specific to a dwelling of the same internal volume as the Holywell test house and to the window opening behaviour scenario applied in this study.

By comparison with the window opening behaviour defined in this paper, which causes an additional heat loss of $4.1 \mathrm{~W} / \mathrm{K}$, a window opening behaviour which leads to an additional heat loss of $15 \mathrm{~W} / \mathrm{K}$ seems rather extreme. If it were to occur however, this window opening behaviour would cause an increase in the total heat loss from a dwelling of more than $10 \%$ for dwellings with an HLC of $145 \mathrm{~W} / \mathrm{K}$ or lower. This demonstrates that window opening could cause a significant additional heat loss in some higher performing houses, or for more extreme window opening behaviours.

\section{DISCUSSION}

A linear relationship between infiltration rate and window opening was revealed by this study which concurs with the results of the only other similar study found in the literature (HowardReed et al., 2002). This study was carried out in two occupied houses in America using a 
tracer gas decay method, which allowed measurements in different weather conditions over a period of several months and with different combinations of open windows. This is particularly significant as it is likely that different combinations of window openings, particularly in different facades, would cause different airflow paths through the house. This is a phenomenon which is not investigated by the method employed in this study where measurements were taken with only one window opened at a time. The fact that a linear relationship was discovered using a tracer gas decay measurement method also adds to the confidence in the findings of this study given the limitations of the blower door testing method. The common findings of the Howard-Reed et al study in occupied houses and those measured in this study act to build confidence in the observed linear relationship between window opening area and additional air infiltration; though it must be noted that they represent a sample of only three houses. Confidence in this relationship is important as it allows the additional heat loss due to that window opening to be simply calculated.

It is likely that the relationship between infiltration rate and opening area would be temporally affected by weather conditions such as a changes in wind speed and direction, or internal-external temperature difference which would cause a different pressure gradient across the dwelling. The effect of these changing conditions cannot be investigated using the blower door method in which a controlled pressure difference is applied evenly across the dwelling, rather than the natural variations that occurs in real life. However, this effect could be offset by research that shows that window opening is less likely for lower external temperatures and higher wind speeds (Fabi et al., 2012; Johnson and Long, 2005).

The influence of window opening during the winter heating season is not included in SAP, and could therefore be a possible cause for the discrepancy between predicted and in-situ energy performance when using the SAP calculation method. The findings of this study do not support this hypothesis for most dwellings and window opening behaviours if causes for a large discrepancy are sought, though they do show that an additional heat loss of $5 \%$ or less due to window opening is reasonable.

As shown in the results section (Figure 6), the effect of window opening relative to the total HLC of a dwelling is dependent upon both the window opening behaviour and its thermal performance. The results of the co-heating tests carried out by Leeds Beckett University (Figure 1) can be used to give some context of typical levels of thermal performance of UK dwellings. Despite the likely skew towards higher-performing dwellings described in the introduction, 24 of the 34 dwellings shown in Figure 1 have a measured HLC of 145W/K or higher. This is the threshold under which a seemingly extreme window opening behaviour (causing an additional heat loss of $15 \mathrm{~W} / \mathrm{K}$ ) was shown to cause a greater than $10 \%$ increase in the total heat loss from a dwelling (Figure 6). It therefore can be said that window opening is unlikely to cause a very significant increase in the heat loss from a dwelling relative to its baseline performance, except in cases of unusually high thermal performance and extreme window opening behaviours.

This is a particularly pertinent finding in relation to post-occupancy evaluation techniques, such as the newly-developed Loughborough In-Use Heat Balance (LIUHB) test (Jack et al., 
2015). In such evaluations the additional heat loss due to window opening is likely to represent an unknown variable due to the difficulty and consequent expense of measuring the time and extent to which windows are open. This unknown also operates in only one direction, acting to erroneously increase and never decrease the measured HLC. The findings of this study provide evidence that acceptably accurate measurement of the thermal performance of most buildings can be taken while a house is occupied, due to the relatively low impact of window opening compared to the total HLC in most houses.

This conclusion is true as long as the window opening behaviour is not 'extreme', however this is currently a subjective judgement as there is a paucity of evidence to define 'typical' and 'extreme' window opening behaviours. A detailed study of window opening behaviour in dwellings is required to establish well-founded estimates of common and extreme examples of real-life behaviour to allow a more objective appraisal.

The results of this study have shown that window opening has the potential to cause a significant additional heat loss relative to the baseline performance of a dwelling in cases of high thermal performance or extreme window opening behaviours (Figure 6). This finding suggests that a method such as the LIUHB test may not be suitable in dwellings of high thermal performance. In these dwellings it is likely that the effect of window opening could introduce a large source of uncertainty to the test, moving the measurement uncertainty outside of the test's estimated accuracy level of $\pm 15 \%$. For instance, in a dwelling with a HLC of lower than $40 \mathrm{~W} / \mathrm{K}$ the window opening behaviour defined in this paper would cause an additional uncertainty of larger than $10 \%$. This finding also highlights the importance of an effective ventilation strategy in dwellings of high thermal performance, and especially high air-tightness, to provide the requisite ventilation without the need for window opening.

\section{CONCLUSIONS}

- A strong linear relationship was observed between the area of window opening and the measured additional air infiltration by a blower door test independent of window location. This finding, based upon blower door measurements, repeats that of Howard-Reed et al who used a tracer gas decay method (Howard-Reed et al., 2002).

- The relationship between opening area and airtightness has been used to calculate the additional heat loss due to a wide variety of possible window opening behaviours.

- It has been shown that window opening does not cause a significant (greater than 5\%) additional heat loss from this particular house compared to the baseline heat loss rate (with all openings closed), except for very extreme window opening behaviours.

- Further analysis suggests that window opening is unlikely to cause a significant additional heat loss relative to the baseline heat loss rate in the majority of dwellings, though it will become increasingly influential in houses of higher thermal performance.

\section{ACKNOWLEDGEMENTS}


This research was made possible by EPSRC support for the London-Loughborough Centre for Doctoral Research in Energy Demand; grant number EP/H009612/1. Measurements from the Loughborough University weather station were kindly provided by Dr Richard Hodgkins of the Department of Geography.

\section{REFERENCES}

Alexander, D.K., Jenkins, H.G., 2015. The Validity and Reliability of Co-Heating Tests Made on Highly Insulated Dwellings, in: 6th International Building Physics Conference, IBPC 2015. Elsevier Ltd.

ASTM, 2012. ASTM E741 - 11. Standard Test Method for Determining Air Change in a Single Zone by Means of a Tracer Gas Dilution. doi:10.1520/E0741-11.2.

ATTMA, 2010. ATTMA Technical Standard 1. Measuring Air Permeability of Building Envelopes (Dwellings). October 2010 Issue.

BRE, 2011. SAP 2009 The Government's Standard Assessment Procedure for Energy Rating of Dwellings. Watford.

BRE, 2013. SAP 2012 - The Government' s Standard Assessment Procedure for Energy Rating of Dwellings. Watford.

Butler, D., Dengel, A., 2013. Review of Co-Heating Test Methodologies (NF 54). doi:978-184806-351-8

Dubrul, C., 1988. TN 23: Inhabitant Behaviour with Respect to Ventilation - A Summary Report of IEA Annex VIII, AIVC Technical Note 23.

Everett, R., 1985. Rapid Thermal Calibration of Houses Report ERG055. London.

Fabi, V., Andersen, R.V., Corgnati, S., Olesen, B.W., 2012. Occupants’ window opening behaviour: A literature review of factors influencing occupant behaviour and models. Build. Environ. 58, 188-198. doi:10.1016/j.buildenv.2012.07.009

Fox, J., 2008. A Study of Occupant Controlled within Ventilation UK Dwellings. University College London.

H.M. Government, 2013. The Building Regulations 2010. Conservation of Fuel and Power Approved Document Part L1A (2013 version). United Kindgom.

Howard-Reed, C., Wallace, L. a., Ott, W.R., 2002. The Effect of Opening Windows on Air Change Rates in Two Homes. J. Air Waste Manage. Assoc. 52, 147-159. doi:10.1080/10473289.2002.10470775

Jack, R., Loveday, D., Allinson, D., Porritt, S.M., 2015. Practical Measurement of the Thermal Performance of Houses. Innov. Res. Focus 6-7. 
Johnson, T., Long, T., 2005. Determining the frequency of open windows in residences: a pilot study in Durham, North Carolina during varying temperature conditions. J. Expo. Anal. Environ. Epidemiol. 15, 329-49. doi:10.1038/sj.jea.7500409

Johnston, D., Miles-Shenton, D., Farmer, D., Wingfield, J., 2013. Whole House Heat Loss Test Method (Coheating). Leeds.

Roulet, C., Foradini, F., 2002. Simple and cheap air change rate measurement using CO2 concentration decays. Int. J. Vent. 1, 39-44.

Sherman, M.H., 1987. Estimation of infiltration from leakage and climate indicators. Energy Build. 10, 81-86. doi:10.1016/0378-7788(87)90008-9

Stafford, A., Bell, M., Gorse, C., 2012. Building Confidence - A working paper. Leeds.

Zero Carbon Hub, NHBC Foundation, 2010. Carbon compliance for tomorrow's new homes; Topic 4: Closing the gap between design and built performance. London. 